\title{
Leishmania (Leishmania) major-infected Rhesus Macaques (Macaca mulatta) Develop Varying Levels of Resistance against Homologous Re-infections
}

\author{
VF Amaral, A Teva, R Porrozzi*, AJ Silva, MS Pereira, MP Oliveira-Neto**, \\ G Grimaldi Jr/ ${ }^{+}$
}

Departamento de Imunologia *Departamento de Ultraestrutura e Biologia Celular, Instituto Oswaldo CruzFiocruz **Hospital Evandro Chagas-Fiocruz, Av. Brasil 4365, 21045-900 Rio de Janeiro, RJ, Brasil

Seven rhesus macaques were infected intradermally with $10^{7}$ promastigotes of Leishmania (Leishmania) major. All monkeys developed a localized, ulcerative, self-healing nodular skin lesion at the site of inoculation of the parasite. Non-specific chronic inflammation and/or tuberculoid-type granulomatous reaction were the main histopathological manifestations of the disease. Serum Leishmania-specific antibodies (IgG and IgG1) were detected by ELISA in all infected animals; immunoblot analyses indicated that numerous antigens were recognized. A very high degree of variability was observed in the parasite-specific cell-mediated immune responses [as detected by measuring delayed-type hypersensitivity (DTH) reaction, in vitro lymphocyte proliferation, and gamma interferon (IFN- $\gamma$ ) production] for individuals over time post challenge. From all the recovered monkeys (which showed resolution of the lesions after 11 weeks of infection), 57.2\% (4/7) and 28.6\% (2/7) animals remained susceptible to secondary and tertiary infections, respectively, but the disease severity was altered (i.e. lesion size was smaller and healed faster than in the primary infection). The remaining monkeys exhibited complete resistance (i.e. no lesion) to each rechallenge. Despite the inability to consistently detect correlates of cell-mediated immunity to Leishmania or correlation between resistance to challenge and DTH, lymphocyte transformation or IFN- $\gamma$ production, partial or complete acquired resistance was conferred by experimental infection. This primate model should be useful for measuring vaccine effectiveness against the human disease.

Key words: rhesus macaques - Macaca mulatta - nonhuman primates - experimental leishmaniasis Leishmania (L.) major - immune responses - histopathology

Protozoan parasites of the genus Leishmania are associated with a broad spectrum of diseases, ranging from mild cutaneous to lethal visceral forms. The outcome of leishmanial infection in humans depends largely on the immune responsiveness of the host and the virulence of the infecting parasite strain. When infected with Leishmania, especially species causing the more benign

\footnotetext{
This work was supported by grants from Fiocruz and Faperj, and the UNDP/World Bank/WHO Special Program for Research and Training in Tropical Diseases. The data presented in this paper have been submitted by VFA as part of a thesis for a PhD degree in Cellular and Molecular Biology at Fiocruz (Rio de Janeiro, Brazil). Present address: Departamento de Imunobiologia, Universidade Federal Fluminense, Outeiro de São João Batista s/nํㅡ, 24210-000 Niteroi, RJ, Brasil

${ }^{+}$Corresponding author. Fax: +55-21-2280.1589. E-mail: grimaldi@gene.dbbm.fiocruz.br

Received 14 November 2000

Accepted 18 April 2001
}

self-healing cutaneous leishmaniasis (CL) forms, most humans develop an effective cell-mediated immunity that resolves the infection and usually confers clinical protection against reinfection (Grimaldi \& Tesh 1993). Both Leishmania-reactive $\mathrm{CD}^{+}$and $\mathrm{CD}^{+} \mathrm{T}$ cells are associated with cure of human CL (Carvalho et al. 1985, Da-Cruz et al. 1994). However, T lymphocytes reactive to leishmanial antigens may also participate in the development of chronic and destructive mucosal lesions (Conceição-Silva et al. 1990, Pirmez et al. 1993).

The use of murine models for the study of immunology of CL has greatly improved our understanding of the regulation of the immune response and of the cellular immune mechanisms involved in host resistance and susceptibility to leishmanial infection. Inoculation of genetically resistant inbred strains of mice with $L$. (L.) major results in control and resolution of $\mathrm{CL}$. The protective immunity to infection is dependent on the ability of resistant hosts to mount an IL-12 driven CD4+ type 1 helper T-cell (Th1) response. In contrast, the pro- 
gressive and fatal infections that develop in more susceptible mouse strains are correlated with activation of the Th2 cytokines IL-4, IL-5, and IL-10, that promote humoral immunity (Reiner \& Locksley 1995, Sjölander et al. 1998).

Current research employing mouse models is also providing the foundation for studies designed to identify leishmanial protective immunogens and the immune mechanisms responsible for immunity in vaccinated mice (Reed \& Scott 1993). However, small experimental animals may not be good predictors of human responses. Simian species most closely related to humans should be more attractive as animal models to evaluate the safety and immunogenicity of vaccines. The hominoid primates (chimpanzees, orangutans, gorillas, and gibbons), which diverged from humans over 5 million years ago, are the most likely to mimic accuratly the disease state and the immunological response to infection (Kennedy et al. 1997a). However, cost considerations and other factors (great apes are endangered species) for using hominoid primate species in biomedical studies represent serious limitations. Next in evolutionary distance are Old World monkeys (macaques, baboons, mandrills, and mangageys), which diverged from the human line between 15 and 20 million years ago. Most distantly related to humans (over 30 million years apart) are the New World monkeys (aotus, owl, cebus monkeys, and marmosets) (Kennedy et al. 1997b). Genetic studies have shown that class I and class II major histocompatibility complex (MHC) products in great apes and nonhominoid Old World monkeys much resemble their human counterparts; in contrast, New World monkeys have a condensed or smaller MHC as compared to humans (reviewed in Kennedy et al. 1997a). Therefore, vaccine trials in Old World primates will probably not be hindered due to divergence of MHC molecules (Prilliman et al. 1996).

A variety of studies have examined the susceptibility of Old and New World monkeys to infection and subsequent disease induction by various Leishmania species (Dennis et al. 1986, Lujan et al. 1986, Pung \& Kuhn 1987, Olobo et al. 1992, Gicheru et al. 1995). Nonhuman primate models have also provided valuable data on the efficacy of putative vaccine candidates against leishmaniasis (Olobo et al. 1995, Kenney et al. 1999, Gicheru et al. 2001). We have previously examined the Asian rhesus macaques as an experimental model for study of CL caused by $L$. (L.) amazonensis infection (Amaral et al. 1996, 2000). In the present study, $M$. mulatta monkeys were infected with $L$. (L.) major and the patterns of primary and challenge infections and immune responses were followed. An important aspect of this animal system in experimental CL lies in the reproduction of clinical events that are common in $L$. (L.) major-infected patients, namely, the self-healing disease and resistance to homologous challenges, indicating development of an acquired immunity.

\section{MATERIALS AND METHODS}

Animals - A total of ten laboratory-bred and -reared young adult (3- to 8-year-old, weighting between 4,600 and 10,560 g) male rhesus macaques (M. mulatta) obtained from the Fiocruz rhesus colony were used. Experimental animals were housed indoors in individual steel squeeze-back cages in a temperature $\left(25^{\circ} \mathrm{C}\right)$ - and humidity $(60$ $\pm 5 \%$ ) - controlled environment. Water was provided ad libitum via an automatic watering system, and High Protein Monkey Diet (NUVILAB; Ministério da Agricultura e Reforma Agrária, Brasil), supplemented with eggs, fruits and vegetables, was fed twice daily. The primate facilities are maintained according to the guidelines of the Committee on the Care and Use of Laboratory Animals of the Institute of Laboratory Animal Resources, National Research Council and Health and Human Services (NIH: MD, USA).

The experiments were conducted using a protocol approved by the Institutional Committee of the Center for Biological Evaluation and Care of Research Animals (CEUA-Fiocruz). The monkeys were aclimatized to the laboratory conditions for at least two weeks before the experimental procedures were begun. Animals were anesthetized before infection and prior to each sampling or testing procedure. Monkeys were initially restrained in their cages, and subsequently they were given, intramuscularly, Ketamine (Ketalar: Ketamine hydrochloride; Parke Davis; $10-40 \mathrm{mg} / \mathrm{kg}$ body weight) for anesthesia.

Parasites and experimental infections - The strain LV39 (MRHO/SU/59/P) of $L$. (L.) major was supplied by Dr SM Beverley, Washington University in St. Louis, Missouri, USA. The strain was typed by serodeme and zymodeme analyses (Grimaldi et al. 1991) in our laboratory before being used for infection. The parasite was maintained by serial subcutaneous passage in hamsters. To obtain suspensions of promastigotes for experimental infections, tissue from chronically infected hamsters was cultured initially in NNN blood agar medium. When promastigotes appeared, the parasites were passaged (no more than three times) into Schneider's Drosophila medium (Gibco), supplemented with $10 \%$ heat-inactivated fetal bovine serum. Parasites were harvested (stationary phase), washed three times using centrifugation in phosphate-buffered saline (PBS), and counted in a Neubauer hemocytometer before use for infection. 
Seven rhesus macaques were each infected by intradermal inoculation of $1 \times 10^{7}$ stationary phase promastigotes in $0.1 \mathrm{ml}$. The various challenge and rechallenge experiments were performed as follows. The animals were initially infected by injecting the promastigote suspension in the area below the brow (orbit) of the right eye and, 26 and 40 weeks later, they were challenge-infected in the opposite orbit (secondary infection) and in the left forearm (tertiary infection) respectively with identical numbers of parasites. Three healthy monkeys, designated as control, were inoculated with PBS.

Pathology - The size and appearance of leishmanial lesions (lesion development) was followed sequentially. Lesion area was calculated using the formula $\pi r_{1} r_{2}$, as described by Wilson et al. (1979). Skin biopsies were removed from the border of cutaneous lesions during active stages (between three and six weeks post-inoculation) using a $4 \mathrm{~mm}$ punch and fixed in 10\% buffered formalin. Paraffin sections were prepared from central and peripheral zones of the lesion and stained with hematoxylin-eosin.

Leishmanin skin test (LST) - The Leishmaniaderived antigens or leishmanin [consisting of pooled heat-killed $L$. (L.) major, $L$. (L.) amazonensis, and L. (Viannia) guyanensis promastigotes suspended in PBS with $0.5 \%$ phenol] used for skin testing of the primates was prepared at the Fiocruz (Biomanguinhos Unit), Brazil. A volume $0.1 \mathrm{ml}$ containing $5 \times 10^{6}$ parasites was injected into the left forearm. Delayed-type hypersensitivity (DTH) reactions were measured as skin indurations at the site of injection (Fig. 2D) after $72 \mathrm{~h}$ using the ballpoint pen method (Agwale et al. 1998). An average induration diameter of equal or more than $5 \mathrm{~mm}$ was considered as a positive LST.

Lymphocyte blastogenesis assay - The methods followed for peripheral blood leukocytes (PBL) preparation and proliferation assays were as described (Amaral et al. 1996). Purified PBL were cultured at $2 \times 10^{6}$ viable cells $\mathrm{ml}^{-1}$ in the presence of optimal culture concentration of mitogen (Phytohemagglutinin PHA-P at $12.5 \mu \mathrm{g} \mathrm{ml}^{-1}$; Sigma) or parasite antigen (10 $\mu$ g protein/well). The soluble leishmanial antigens (SLA) for in vitro blast transformation assays were prepared from $L$. (L.) major (LV39) promastigotes, according to the method described by Dennis et al. (1986). Cultures were incubated at $37^{\circ} \mathrm{C}$ in a humidified atmosphere containing $5 \% \mathrm{CO}_{2}$ for three days in the case of mitogen or for four days in the case of antigens. The cells were pulsed with $\left[{ }^{3} \mathrm{H}\right]$ thymidine (Amersham, Co., U.K.; $1 \mu \mathrm{Ci} /$ well; $5 \mu \mathrm{Ci} / \mathrm{m} M$ ) over the last $18 \mathrm{~h}$ and harvested onto glass fiber filter mats (Titertek, FlowLab). Radioactive incorporation into DNA was determined by liquid scintillation spectrometry. Results are expressed as the stimulation index (SI, mean cpm stimulated cultures/mean cpm unstimulated cultures). To determine significance, data from the lymphocyte proliferative responses (LPR) of infected monkeys were compared with those of healthy animals (control group) using the unpaired Student's $t$-test. Concordance between the LST and the in vitro LPR was assessed by the ratio: number of monkeys positive by both tests + number of those negative by both tests : total number of individual tested (Sassi et al. 1999).

The staining and cytofluographic analysis of stimulated PBL was as described previously (Amaral et al. 1996). For the analyses of phenotype of responding $\mathrm{T}$ cell subsets of infected animals, the following commercial monoclonal antibodies were employed: CD4 helper/inducer T cell subset (OKT4 antibody; Ortho Diagnostic Systems, Raritan, NJ), CD8 suppressor/cytotoxic T cell subset (Leu 2a antibody; Becton-Dickinson, San Jose, CA), and anti-CD25 (for IL-2 receptor; BectonDickinson).

Interferon- $\gamma$ production by stimulated cells and measurements of IFN- $\gamma$ - Purified PBL were ad-

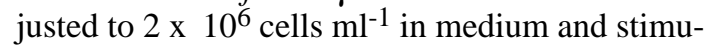
lated with either PHA-P or SLA. Cell culture medium were pooled from duplicate wells after $72 \mathrm{~h}$ of stimulation. A rhesus monkey IFN- $\gamma$ ELISA immunoassay kit obtained commercially (Biosource International, Camarillo, CA) was used for the in vitro quantitative determination of IFN- $\gamma$ in the supernatants. Streptavidine-Peroxidase (HRP) conjugate and stabilized chromogen, Tetramethylbenzidine (TMB) substrate were used for detection, as per the manufacturer's instructions. A standard curve (obtained for the various standards over the range of 0 to $1000 \mathrm{pg} \mathrm{ml}^{-1}$ IFN- $\gamma$ ) was run with each assay. IFN- $\gamma$ concentrations for unknown samples and controls were read from the standard curve plotted.

Serologic assays - Antigen-specific serum antibody concentrations were determined by adapting a standard ELISA technique (Almeida et al. 1996) to detect rhesus immunoglobulins, using microtiter plate wells coated with SLA, sera of rhesus monkeys (1:50 dilution), and diluted rabbit anti-monkey immunoglobulin $\mathrm{G}(\mathrm{IgG})$-peroxidase (Sigma Chemical Co., St. Louis-MO, USA), or rabbit anti-human IgM-HRP conjugate (Biomanguinhos, Fiocruz). The optimal leishmanial antigen concentration $(100 \mu \mathrm{g} / \mathrm{ml})$, as well as serum and conjugate dilutions were determined by checkerboard titration using known positive and negative control monkey sera. Subclass-specific 
antibodies were detected employing cross-reactive (Shearer et al. 1999) anti-human IgG1 (clone 8c/ 6-39), IgG2 (clone HP-6014), and IgG4 (clone HP 6025 ) biotinylated monoclonal antibodies obtained commercially (Sigma). The reaction was revealed with biotin-avidin peroxidase system. The monoclonal antibodies were diluted 1:800 and avidinperoxidase was diluted 1:1,000. The substrate consisted of $0.04 \%$ o-phenylenediamine (OPD) dihidrochloride and $0.012 \%$ hydrogen peroxidase in phosphate-citrate buffer, $\mathrm{pH}$ 5. All sera were tested in duplicate and those yielding positive results were re-tested at least once. The lower limit of positivity (cut off) was determined by mean of negative control +2 s.d. (Richardson et al. 1983) .

Moreover, detection of serum antibodies to leishmanial (LV39) antigens was performed by Western blot analysis. Briefly, the SLA extracts were resolved by sodium dodecyl sulphate-polyacrylamide gel electrophoresis (SDS-PAGE) using $12 \%$ slab gels in non-reducing conditions, and electrophoretically transferred to nitrocellulose paper (Schleider and Schuell, Keene, NH). The nitrocellulose strips were incubated overnight at $4^{\circ} \mathrm{C}$ with either immune sera obtained from infected primates or human CL patients (positive controls) or sera from healthy macaques (negative controls). Subsequently after washing, strips were incubated with either rabbit anti-monkey IgG-peroxidase conjugate or rabbit anti-human IgG (Sigma), or anti-human IgG1 (clone 8c/6-39) biotinylated monoclonal antibody. After rinsing, strips were developed in a satured solution of 3,3'diaminobenzidine in Tris buffer ( $\mathrm{pH}$ 7.4) containing $0.01 \% \mathrm{H}_{2} \mathrm{O}_{2}$. The techniques have been described in detail previously (Leon et al. 1992).

\section{RESULTS}

Establishment of infection and lesion development - As illustrated (Figs 1, 2), all L. (L.) majorinfected rhesus monkeys inoculated (Experiment 1) in the orbit of the right eye with $10^{7}$ virulent promastigotes developed nodular skin lesions at the site of inoculation. An erythematous papule was first visible at 1-2 weeks postinoculation (wk p.i.); lesion development progressed rapidly (nodules varying between approximately 20 to $160 \mathrm{~mm}^{2}$ ), peaking at 3 to 8 wk p.i., and all lesions ulcerated (after 3 wk p.i.) and subsequently regressed and healed (macroscopically, primary lesions had disappeared from infected animals by 11 wk p.i.). In contrast, the convalescent monkeys (which had recovered from primary skin lesions) developed significant levels of resistance to subsequent challenges using the same parasite strain/dose. As shown (Fig. 1) some of the recovered monkeys remained susceptible to secondary infection (4/7 animals; $57.2 \%)$ and/or to tertiary infection (2/7 animals; $28.6 \%$ ), but in general the lesions were smaller and healed faster than in the initial infection. The remaining monkeys developed complete clinical protection in that no skin lesion developed after each rechallenge.

Pathology - A firm elastic nodule developed (after $3 \mathrm{wk}$ p.i.) at the site of parasite inoculation. The chronic nodular lesions (Fig. 2A-B) diminished in size after spontaneous ulceration and healing of the CL. At the biopsy animals showed histological evidence of infection. In early phases (3-4 wk p.i.) of the developing primary ulcerated skin lesions (data not shown), the histopathological findings in the dermis showed a non-specific chronic mononuclear infiltrate, containing indistinctly delimited differentiated macrophage accumulations and neutrophils (apparently associated with lysis of few parasitized macrophages). In late stages (6-8 wk p.i.), differentiated macrophages, interspersed with more or less numerous lymphocytes and plasma cells, represented the principal feature in this inflammatory process, which evolved to the formation of tuberculoid-type granulomatous nodules (Fig. 2C). The granulomas were surrounded by a diffuse mononuclear infiltrate containing giant cells. The histological picture of lesions (biopsy samples obtained at 2-3 wk p.i.) developed in animals after secondary and/or tertiary infections was not the exudative cellular reaction (commonly found at this stage following primary infection), but an earlier formation of mature granulomatous nodules.

Cell-mediated immune responses - DTH reaction to LST was used as in vivo correlate of cellu-

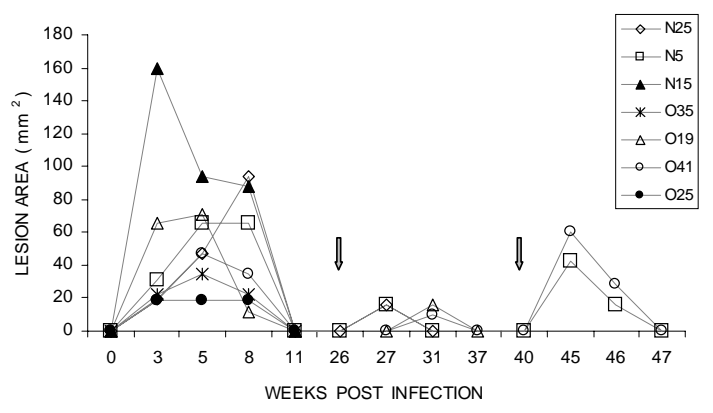

Fig 1: time course of skin lesion development in Leishmania (Leishmania) major-infected rhesus macaques. The animals were initially inoculated in the orbit of the right eye with $1 \mathrm{x}$ $10^{7}$ L. (L.) major promastigotes. After recovery from the primary infection, the primates were subsequently challenged at distinct time points (as indicated by arrows) in the opposite area (secondary infection) and in the left forearm (tertiary infection) respectively with identical numbers of parasites. Lesions were scored by calculating the total lesion area as indicated (see Materials and Methods). 

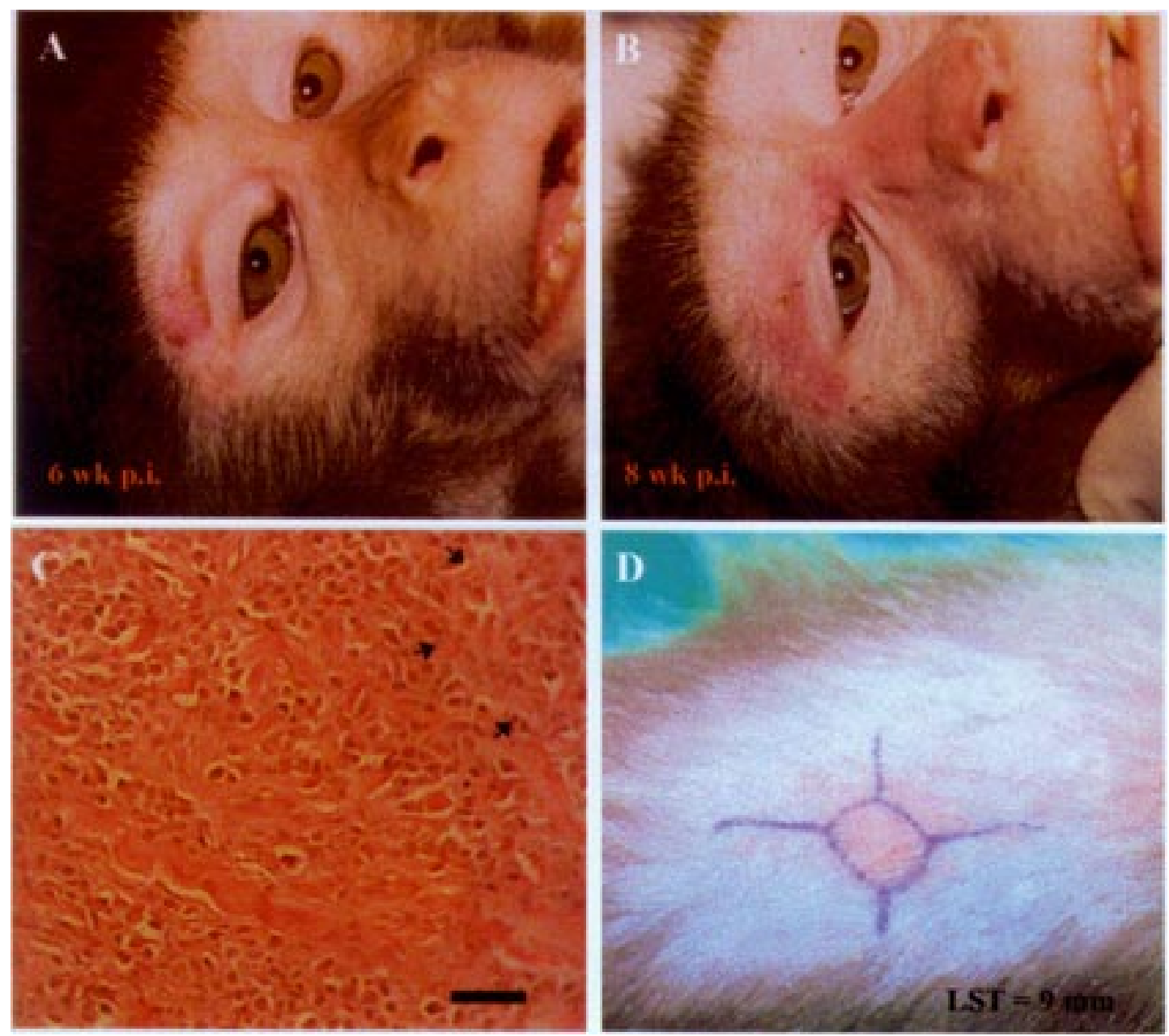

Fig 2: self-healing cutaneous leishmaniasis in naive rhesus macaques infected with Leishmania (Leishmania) major. Animals at different time points of infection as indicated (A: Rh O35 and B: Rh O25), showing nodular ulcerated skin lesions limited to the infected area; $\mathrm{C}$ : section from a developing skin lesion (Rh O35), showing a mononuclear cell infiltrate containing differentiated macrophages (arrows), typical of a cell-mediated immune response-induced granulomatous reaction. H\&E stain. Bar $=80 \mu \mathrm{m}$; D: leishmanin skin test positive reaction detected (Rh O35) at 14 weeks post-infection.

lar immunity. No cell-mediated reaction to skin test parasite antigen developed in monkeys prior to infection, but LST reactivity (range 3-10 mm) was detected as early as 3 wk p.i. and continued up to 63 wk p.i. (Fig. 3). In spite of a transient immunounresponsiviness to the LST observed in individuals over time post challenge, the pooled leishmanin identified all the monkeys with active or healed CL. The reaction sizes found among positive animals did not correlate however with lesion development.

In spite of wide variations from one infected animal to another (as shown by some large SD values), the findings indicate that a proliferative response in vitro to SLA of blood lymphocytes develops during primary and challenge infections (Fig. 4). Parasite-specific LPR were negative (SI<
2.5) in all animals at the initiation of infection, and PBL of animals were comparably responsive to control mitogen PHA-P prior to and throughout infection (data not shown). A positive reaction developed as early as $3 \mathrm{wk}$ p.i. (mean \pm SD of SI $9.7 \pm 5.4$ ) and subsequently continued to increase, peaking at 8 wk p.i. (mean \pm SD of SI $16.3 \pm 8.8$ ), but SI mean values $(3.6 \pm 2.7$ at 59 wk p.i.) were significantly lower after the tertiary challenge than during the primary or secondary infection. No positive correlation $(r=0.36, \mathrm{p}>0.05)$ was observed between the overall lymphocyte blastogenesis positivity and LST induration size values.

Moreover, the supernatant IFN- $\gamma$ levels produced by responding $\mathrm{T}$ cells following in vitro $\mathrm{Ag}$ stimulation were also determined (data not shown). No evidence of Ag-specific IFN- $\gamma$ response was 
detected in these animals during the initial infection when compared with non-infected controls. In fact only two individuals, after challenge, produced IFN- $\gamma(30-40 \mathrm{pg} / \mathrm{ml})$ above the level observed at time zero $(10 \mathrm{pg} / \mathrm{ml})$. The sensitivity of the assay was evidently low since supernatants from PHA stimulated PBL cell cultures produced only marginal levels of IFN- $\gamma$ prior to and throughout primary infection.

Antigen-stimulated PBL cells from all primates were examined (during 45-60 wk p.i.) for phenotype analysis of cell surface antigens. Results showed variation (but not significantly; $\mathrm{P}>$ 0.05 ) in the ratio of $\mathrm{CD} 4+$ to $\mathrm{CD} 8+$ responding $(\mathrm{CD} 25+) \mathrm{T}$ cells in experimental animals

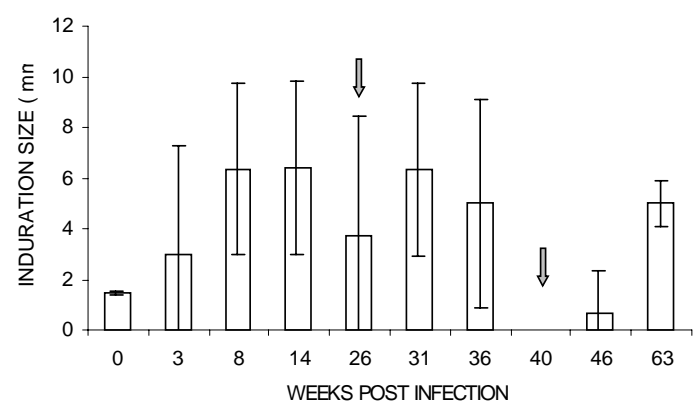

Fig 3: delayed-typed hypersensitivity reaction to skin test parasite antigen was measured to assess levels of cell-mediated immunity in vivo developed in Leishmania (Leishmania) major-infected rhesus macaques. A volume of $0.1 \mathrm{ml}$ containing $5 \times 10^{6}$ heat-killed promastigotes was injected into the shaven area of the right forearm. Skin induration was read after $72 \mathrm{~h}$ and results are expressed as the diameter of skin induration in millimetres. Data are mean \pm SD of 7 infected monkeys. Animals were rechallenged at different time points as indicated (arrows).

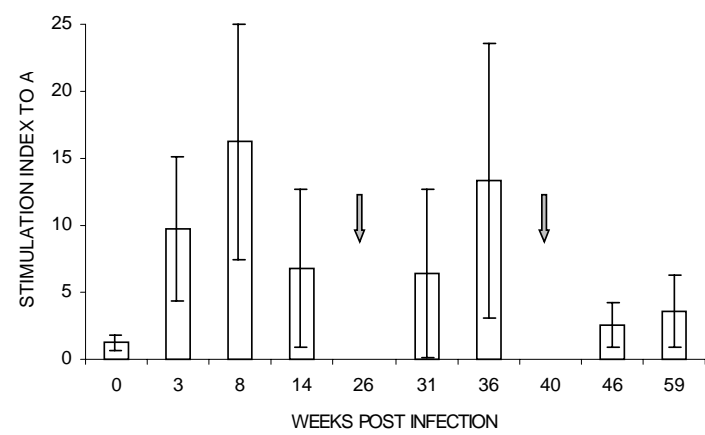

Fig 4: parasite-specific proliferative responses of blood lymphocytes from rhesus monkeys are detected during primary and challenge infections. Cell suspensions of purified peripheral blood leukocytes were restimulated in vitro in the presence of soluble leishmanial antigens prepared from Leishmania (Leishmania) major. Cell proliferation was assessed by measuring $\left[{ }^{3} \mathrm{H}\right]$ thymidine incorporation. Results are expressed as the stimulation index (SI, mean cpm stimulated cultures/ mean cpm unstimulated cultures). Data are mean \pm SD of 7 infected monkeys. Animals were rechallenged at different time points (arrows).
(CD4:CD8 mean ratio, 1.65; range, 0.8-2.6) as compared to uninfected controls (CD4:CD8 mean ratio, 1.95; range, 1.1-3.5).

Antibody responses - Anti-L. (L.) major antibody responses detected by ELISA in experimental animals varied during infection (Fig. 5). IgM response was variable (absorbance values ranging from $0.41 \pm 0.17$ to $0.74 \pm 0.25$ at 1:50 serum dilution), but was not significantly above the absorbance values $(0.48 \pm 0.20)$ of the uninfected animals. In contrast, both total IgG and IgG1 levels were detectable $3 \mathrm{wk}$ p.i. and subsequently continued to increase, peaking at 8 wk p.i. after which levels declined in animals with healing lesion. Following re-challenge, IgM levels did not increase significantly in comparison to primary infection (data not shown), but the IgG and IgG1 titers increased and continued up to 46 wk p.i. No detectable IgG2 or IgG4 antibody responses to Leishmania were observed in control (uninfected) or infected animals.

Western blots of promastigote homogenates were performed employing immune sera (1:100 was taken as the optimal titer, lowest dilution at which control animals gave no signal on the antigen profile) from monkeys at various times post-
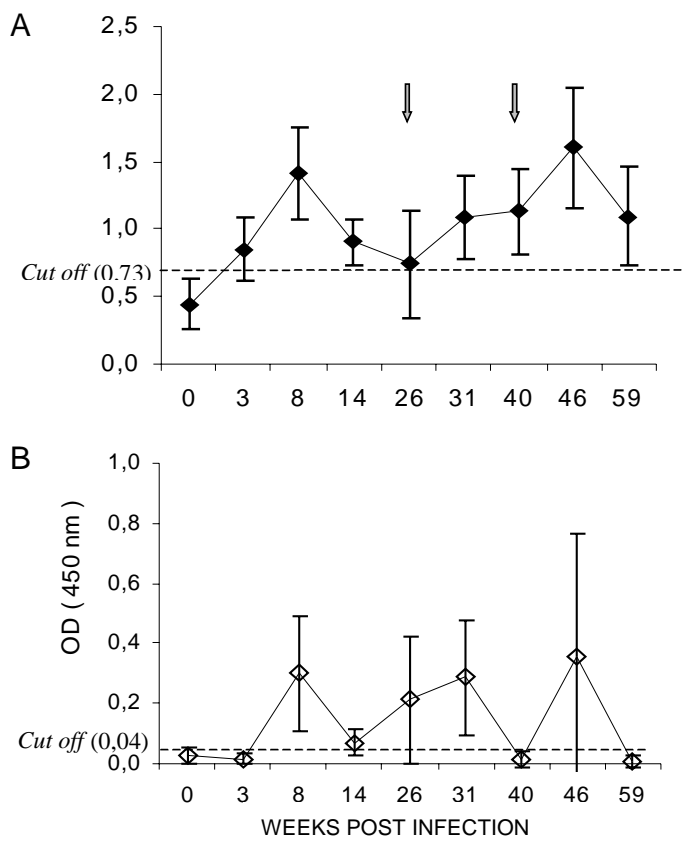

Fig 5: evolution of serum levels of Leishmania-specific antibodies (A, IgG and $\mathrm{B}, \mathrm{IgG} 1)$ in $L$. (L.) major-infected rhesus macaques. Each point represents the optical density value (mean \pm standard deviation) at $450 \mathrm{~nm}\left(\mathrm{OD}_{450}\right)$ of sera from 7 infected monkeys tested (1:50 dilution), as determined by enzyme-linked immunosorbent assay. Animals were rechallenged at different time points as indicated (arrows). 
infection (data not shown). The antibodies (both IgG and IgG1 isotypes) produced by the animals recognized multiple bands ranging from 35 to 210 $\mathrm{kDa}$, but there was variation in the number of antigen components and/or in the intensities of signals. Animals giving high ELISA antibody titers gave stronger reactions and recognized more antigens in western blots.

\section{DISCUSSION}

Localized CL caused by $L$. (L.) major is an endemic parasitic zoonosis in North Africa and the Middle East (WHO/CID/Leish/98.9 Add.1). The disease is generally benign, in that most cases heal spontaneously within three months (Kemp et al. 1994). The experiments recorded here show that $M$. mulatta is susceptible to $L$. (L.) major infection and confirm the potential for this to be used as a nonhuman primate model of the human disease. In spite of a variation observed in the clinical course of infection, each of the experimental animals developed a simple cutaneous lesion which progressed spontaneously to ulceration and complete resolution within about three months. The study shows that both the incubation period and self-cure in $L$. (L.) major-infected rhesus macaques compare well with those observed in humans (Beach et al. 1984). The pathologic features in this model were also very similar to human CL (Ridley \& Ridley 1983), in that the exudative cellular inflammatory process evolved to a granulomatous reaction in developing ulcerated skin lesion. The fact that the tuberculoid-type granulomatous reaction took place much earlier in reinfected animals (as compared with those with primary infection) indicates that histological changes reflect host immune status in CL.

A more marked variation in the clinical course of infection [as compared to $L$. ( $L$. $)$ major] was observed when rhesus monkeys were examined for susceptibility to $L$. (L.) amazonensis (Amaral et al. 1996). These observations suggest that the outcome of leishmanial infection in $M$. mulatta may depends on the biological behaviour (virulence) of the infecting parasite strain. Similarly, the pathologic analyses in $L$. (L.) amazonensis-infected rhesus monkeys indicated that lesions contained amastigotes with a mononucluear infiltrate of macrophages, lymphocytes, and plasma cells, and formation of tuberculoid-type granulomas (Amaral et al. 1996). The granulomas showed a mixture of Tcell subpopulations with the ratio of CD4:CD8 phenotypes less than one. The percentage of cells in the granulomas expressing the MHC class II antigens (HLA-DR+) in active lesions $(95 \pm 7.1 \%)$ was significantly higher $(P<0.005)$ from the healing lesions (42 $\pm 12.7 \%$ ) (Amaral et al. 2000). Re- sults similar to ours were previously reported, studying the infiltrate in the skin of humans with CL (Pirmez et al. 1990, Lima et al. 1994).

Self-cure CL in humans is generally thought to give rise to a long-lasting immunity to reinfection (Alvarado et al. 1989, Kemp et al. 1994). Some observations suggest, however, that immunity conferred by prior self-resolving $L$. braziliensis sp. infection may not always be complete (Saravia et al. 1990). Aditionally, partial protection was reported in a patient who had a previous infection of $L$. (L.) major and became reinfected one year later with the same parasite strain (Killick-Kendrick et al. 1985). In this study, monkeys which had recovered from skin lesions were challenged using an identical inoculum of the same parasite strain. The animals developed distinct levels of clinical resistance (as reflected by either an absence of skin lesion or a smaller size and faster resolution of the lesions as compared to the inicial infection) to each rechallenge, indicating that acquired protective immunity against the parasite occurred. Similar results have been demonstrated in näive (Amaral et al. 1996) or vacinnated (Kenney et al. 1999) $L$. (L.) amazonensis or L. (L.) tropica (Wolf 1976) infected rhesus macaques, as well as in other primates species (Dennis et al. 1986, Githure et al. 1987, Gicheru et al. 2001).

Humans with CL due to $L$. (L.) major develop DTH to intradermal injection of killed promastigotes (LST), and their peripheral mononuclear cells proliferate in response to Leishmania antigens (Kemp et al. 1994, Sassi et al. 1999). Both in vitro lymphocyte proliferative and IFN- $\gamma$ responses tend to increase during healing (Gaafar et al. 1999). Therefore, healing of the skin lesions and immunity in zoonotic CL are believed to be mediated by cell-mediated immune response. In contrast, the DTH response reported in vaccinees as in vivo correlates of cellular-mediated immunity may not indicate resistance to infection (Antunes et al. 1986, Castes et al. 1994). This study shows that the $L$. (L.) major-infected rhesus macaques were equally able to develop parasitespecific cell-mediated immune responses. Despite the inability to consistently detect correlates of cellmediated immunity to $L$. (L.) major, complete or partial resistance was conferred by experimental infection. Correlates of protection were also sought, but they were not consistently found in other nonhuman primate models of human leishmaniasis (Dennis et al. 1986, Lujan et al. 1986, Olobo et al. 1992, Gicheru et al. 1995).

Although marked variation in the magnitude of immune response to Leishmania has been reported in CL patients (Alvarado et al. 1989, Sassi et al. 1999) the observed differences are not in 
agreement with the immune profile of patients with healing CL due to $L$. (L.) major. Our results showed a week correlation $(r=0.36)$ between the DTH reaction assessed by LST and the in vitro LPR of PBL from $L$. $(L$.) major-infected rhesus macaques, as compared to values (98\% concordance) described for patients with active or healed CL caused by the same parasite species (Sassi et al. 1999). However, a positive correlation $(r=0.88)$ was found between the size of skin induration and lymphocyte proliferation in animals with healing lesion at $14 \mathrm{wk}$ p.i. (data not shown).

The fact that SI mean values obtained were significantly lower after the tertiary challenge than during the primary or secondary infection was not expected at all. The biological significance of this decline is not clear, although adult rhesus monkeys may exhibit stress response [such as when removed from their social group to a novel environment (Gust et al. 1993) and/or submitted to excess of manipulation] that might justify the lower response. Alternatively, those animals completely recovered and parasite-free would develop lower or even negative response as well.

Unlike the typical response in humans, little or no IFN- $\gamma$ was detected in supernatants after primary infection (data not shown), which may indicate a limit of the model. Nevertheless, it is very possible that this could in fact represent a falsenegative result, either because the time point to measure the cytokine was not the optimal one (IFN$\gamma$ was measured after up to $72 \mathrm{~h}$ of stimulation), or because the kit was not sensitive enough to detect this production. Although a Th1-like activity response (as revealed by an increased production of IFN- $\gamma$ by the responding $\mathrm{T}$ cells) was associated with CL in vervet monkeys (Cercopithecus aethiops) following secondary rechallenge with L. (L.) major (Olobo et al. 1992), recent data suggest that protection against $C L$ in either vaccinated rhesus macaques (Kenney et al. 1999) or vervets (Gicheru et al. 2001) may require more than the activation of Leishmania-specific IFN- $\gamma$-producing $\mathrm{T}$ cells.

In late stages of infection, no significant variation $(\mathrm{P}>0.05)$ in the ratio of $\mathrm{CD} 4+$ to $\mathrm{CD} 8+$ responding (CD25+) $\mathrm{T}$ cells was found in experimental animals as compared to uninfected controls. However, in the original model description (Amaral et al. 1996), the circulating $T$ cell subpopulations from the L. (L.) amazonensis-infected monkeys vary throughout the course of infection. In early phases of infection blood CD4+ T cells appear to predominate (CD4:CD8 mean ration, 5.0; range 2.5-7.1), but subsequently, an increase in CD8+ T cells was observed (CD4:CD8 mean ration, 1.05; range 0.37-2.1). Moreover, in this model, there was apparently no correlation between lesional $\mathrm{T}$ cell subsets (T-cell ratios favor CD8+ cells in both active and healing lesions) (Amaral et al. 2000) and those found in blood [initially during infection CD4:CD8 mean ratio was 5.0; subsequently, an increase in $\mathrm{CD} 8+\mathrm{T}$ cells was observed (CD4:CD8 mean ration, 1.05)] (Amaral et al 1996).

In this study, immune recognition was confirmed by detection of an antigen specific antibody response. Immunoblot analyses showed that infected monkeys produced antibodies (both IgG and $\mathrm{IgG}_{1}$ isotypes) which bound to a number of Leishmania antigen components, consistent with human data (Leon et al. 1992). A differential decline in leishmanial antigen-specific $\operatorname{IgG}, \operatorname{IgM}, \operatorname{IgE}$, and IgG subclasses was shown in visceral leishmaniasis patients after chemotherapy (Anam et al. 1999), in particular with IgG1 and IgG3 levels being significantly reduced following treatment (Elassad et al. 1994, Ghosh et al. 1995). The decline observed in the $\mathrm{IgG}$ and $\mathrm{IgG} 1$ responses in monkeys with healing lesion is probably due to similar regulatory function of $\mathrm{T}$ cells as described for the murine and human models (Abbas et al. 1996). However, little information is available on the IgG subclasses expressed in the sera of non-human primate species. The data suggest that baboon sera, like human sera, contain four IgG subtypes, whereas macaque sera exhibit only three of the human subclass analogous (Shearer et al. 1999). Southern blot experiments with genomic DNA samples of rhesus monkeys and human $\mathrm{C}$ gamma-specific probes also indicated that $\mathrm{IgG} 3$ gene is not expressed in macaques (Calvas et al. 1999).

In conclusion, this primate model showed that experimental infection confers partial or complete immunity to challenge in a variable proportion of individuals as happens in humans. This difference in protection (contrary to the susceptibility of $\mathrm{BALB} / \mathrm{c}$ mice) provides outcomes that should allow correlates of complete protection to be identified. Furthermore, the ability of candidate vaccines to equal or exceed the rate of protection conferred by experimental infection provides a basis of evaluation of efficacy. Because the incubation period and the disease tempo (i.e., the progression and resolution of skin lesions) were similar to those seen in human CL, the endpoint for prophylaxis and vaccine trials can be easily determined in the rhesus model.

\section{ACKNOWLEDGMENTS}

To Dr Virgílio Ferreira and the staff in the Fiocruz Animal Care Facility for their assistance with daily care and procedures on the macaques; to Drs Sergio G Coutinho and Claude Pirmez (IOC-Fiocruz) for their assistance during of the laboratory work. 


\section{REFERENCES}

Abbas AK, Murphy KM, Sher A 1996. Functional diversity of helper T lymphocytes. Nature 383: 787793.

Agwale SM, Duhlinska DD, Grimaldi Jr G 1998. Response to heterologous leishmanins in cutaneous leishmaniasis in Nigeria - Discovery of a new focus. Mem Inst Oswaldo Cruz 93: 23-27.

Almeida RP, Barral-Netto M, De Jesus AMR, De Freitas LAR, Carvalho EM, Barral A 1996. Biological behavior of Leishmania amazonensis isolated from humans with cutaneous, mucosal, or visceral leishmaniasis in BALB/c mice. Am J Trop Med Hyg 54: 178-184.

Alvarado R, Enk C, Jaber K, Schur L, Frankenburg S 1989. Delayed-type hypersensitivity and lymphocyte proliferation in response to Leishmania major infection in group of children in Jericho. Trans $R$ Soc Trop Med Hyg 83: 189-192.

Amaral VF, Pirmez C, Gonçalves AJS, Ferreira V, Grimaldi Jr G 2000. Cell populations in lesions of cutaneous leishmaniasis of Leishmania (L.) amazonensis-infected rhesus macaques, Macaca mulatta. Mem Inst Oswaldo Cruz 95: 209-216.

Amaral VF, Ransatto VAO, Conceição-Silva F, Molinaro E, Ferreira V, Coutinho SG, McMahonPratt D, Grimaldi Jr G 1996. The Asian rhesus macaques (Macaca mulatta) as an experimental model for study of cutaneous leishmaniasis. Exp Parasitol 82: 4-44.

Anam K, Afrin F, Baneriee D, Pramanik N, Guha SK, Goswami RP, Sahaq SK, Ali N 1999. Differential decline in Leishmania membrane antigen-specific immunoglobulin G (IgG), IgM, IgE, and IgG subclass antibodies in Indian kala-azar patients after chemotherapy. Infect Immun 67: 6663-6669.

Antunes CM, Mayrink W, Magalhães PA, Costa CA, Melo MN, Dias M, Michalick MS, Williams P, Lima AO, Vieira LB, Schettini APM 1986. Controlled field trials of a vaccine against New World cutaneous leishmaniasis. Int J Epidemiol 15: 572-579.

Beach R, Kilu G, Hendricks L, Oster C, Leeuwenberg J 1984. Cutaneous leishmaniasis in Kenya: Transmission of L. major to man by the bite of Phlebotomus duboscqi. Trans R Soc Trop Med Hyg 78: 747-751.

Calvas P, Apoil P, Fortenfant F, Roubinet F, Andris J, Capra D, Blancher A 1999. Characterization of the three immunoglobulin $\mathrm{G}$ subclasses of macaques. Scand J Immunol 49: 595-610.

Carvalho EM, Johnson Jr WR, Barreto E, Marsden PD, Costa JLM, Reed S, Rocha H 1985. Cell mediated immunity in American cutaneous and mucocutaneous leishmaniasis. J Immunol 135: 4144-4148.

Castes M, Blackwell J, Trujillo D, Formica S, Cabrera M, Zorrilla G, Rodas A, Castellanos PL, Convit J 1994. Immune response in healthy volunteers vaccinated with killed leishmanial promastigotes plus BCG. I. Skin-test reactivity, T-cell proliferation and interferon- $\gamma$ production. Vaccine 12: 1041-1051.

Conceição-Silva F, Dórea RC, Pirmez C, Schubach A, Coutinho SG 1990. Quantitative study of Leishmania braziliensis braziliensis reactive $\mathrm{T}$ cells in pe- ripheral blood and in the lesions of patients with American mucocutaneous leishmaniasis. Clin Exp Immunol 79: 221-226.

Da-Cruz AM, Conceição-Silva F, Bertho AL, Coutinho SG 1994. Leishmania-reative CD4 and CD8 T cells associated with cure of human cutaneous leishmaniasis. Infect Immun 62: 2614-2618.

Dennis VA, Lujan R, Chapman Jr WL, Hanson WL 1986. Leishmania donovani: cellular and humoral immune responses after primary and challenge infections in squirrel monkeys, Saimiri sciureus. Exp Parasitol 61: 319-334.

Elassad AMS, Younis SA, Siddig M, Gravson J, Petersen E, Ghalib HW 1994. The significance of blood levels of $\operatorname{IgM}, \mathrm{IgA}, \mathrm{IgG}$ and IgG subclasses in Sudanese visceral leishmaniasis patients. Clin Exp Immunol 95: 294-299.

Gaafar A, Veress B, Permin H, Kharazmi A, Theander TG, El Hassan AM 1999. Characterization of the local and systemic immune responses in patients with cutaneous leishmaniasis due to Leishmania major. Clin Immunol 91: 314-320.

Ghosh MK, Dasgupta S, Ghose AC 1995. Immunoglobulin $\mathrm{G}$ sub-class-specific antileishmanial antibody responses in Indian kala-azar and post kala-azar dermal leishmaniasis. Clin Diagn Lab Immunol 2: 291296.

Gicheru MM, Olobo JO, Anjili CO, Orago AS, Modabber F, Scott P 2001. Vervet monkeys vaccinated with killed Leishmania major parasites and interleukin-12 develop a type 1 immune response but are not protected against challenge infection. Infect Immun 69: 245-251.

Gicheru MM, Olobo JO, Kariuki TM, Adhiambo C 1995. Visceral leishmaniasis in vervet monkeys: Immunological responses during asymptomatic infections. Scand J Immunol 41: 202-208.

Githure JI, Reid GD, Binhazim AA, Anjili CO, Shatry AM, Hendricks LD 1987. Leishmania major: the suitability of East African nonhuman primates as animal models for cutaneous leishmaniasis. Exp Parasitol 64: 438-447.

Grimaldi Jr G, Tesh RB 1993. Leishmaniasis of the New World: current concepts and implications for future research. Clin Microbiol Rev 6: 230-250.

Grimaldi Jr G, Momen H, Naiff RD, McMahon-Pratt D, Barrett TV 1991. Characterization and classification of leishmanial parasites from humans, wild animals, and sand flies in the Amazon region of Brazil. Am J Trop Med Hyg 44: 645-661.

Gust DA, Gordon TP, Hambright MK 1993. Response to removal from and return to a social group in adult male rhesus monkeys. Physiol Behav 53: 599-602.

Kemp M, Hey AS, Kurtzhals JA, Christensen CB, Gaafar A, Mustafa MD, Kordofani AA, Ismail A, Kharzmi A, Theader TG 1994. Dichotomy of the human T cell response to Leishmania antigens. I. Th1-like activity response to Leishmania major promastigote antigens in individuals recovered from cutaneous leishmaniasis. Clin Exp Immunol 96: 410-415.

Kennedy RC, Shearer MH, Hildebrand WH 1997a. Nonhuman primate models to evaluate vaccine safety 
and immunogenicity. Vaccine 15: 903-908.

Kennedy RC, Shearer MH, Hildebrand WH, Simmonds RS 1997b. Nonhuman primates and their use in immunologically based investigations. The Immunologist 5/5: 150-156.

Kenney RT, Sacks DL, Sypek JP, Vilela L, Gam AA, Evans-Davis K 1999. Protective immunity using recombinant human IL-12 and alum as adjuvants in a primate model of cutaneous leishmaniasis. $J$ Immunol 163: 4481-4488.

Killick-Kendrick R, Bryceson ADM, Peter W, Evans DA, Leaney AJ, Rioux JÁ 1985. Zoonotic cutaneous leishmaniasis in Saudi Arabia: Lesions healing naturally in man followed by a second infection with the same zymodeme of Leishmania major. Trans $R$ Soc Trop Med Hyg 79: 363-365.

Leon LL, Barral A, Machado GMC, Grimaldi Jr G 1992. Antigenic differences among Leishmania amazonensis isolates and their relationships with distinct clinical forms of the disease. Mem Inst Oswaldo Cruz 87: 229-234.

Lima HC, Vasconcelos AW, David JR, Lerner EA 1994. American cutaneous leishmaniasis: in situ characterization of the cellular immune response with time. Am J Trop Med Hyg 50: 743-747.

Lujan R, Dennis VA, Chapman Jr WL, Hanson WL 1986. Blastogenic responses of peripheral blood leukocytes from owl monkeys experimentally infected with Leishmania braziliensis panamensis. Am J Trop Med Hyg 35: 1103-1109.

Olobo JO, Anjili CO, Gicheru MM, Mbati PA, Kariuki TM, Githure JI, Koech DK, McMaster WR 1995. Vaccination of vervet monkeys against cutaneous leishmaniasis using recombinant Leishmania 'major surface glycoprotein' (gp63). Vet Parasitol 60: 199-212.

Olobo JO, Reid GD, Githure JI, Anjili CO 1992. IFNgamma and delayed-type hypersensitivity are associated with cutaneous leishmaniasis in vervet monkeys following secondary rechallenge with Leishmania major. Scand J Immunol (Suppl.) 11: 48-52.

Pirmez C, Cooper C, Paes-Oliveira M, Schubach A, Torigian VK, Modlin RL 1990. Immunologic responsiveness in American cutaneous leishmaniasis lesions. J Immunol 145: 3100-3104.

Pirmez C, Yamamura M, Uyemura K, Paes-Oliveira M, Conceição-Silva F, Modlin RL 1993. Cytokine pat- terns in the pathogenesis of human leishmaniasis. $J$ Clin Investig 91: 1390-1395.

Prilliman K, Lawlor D, Ellexson M, McElwee N, Confer D, Cooper DKC, Kennedy RC, Hildebrand W 1996. Characterization of baboon class I major histocompatibility molecules. Transplantation 61: 989-996.

Pung OJ, Kuhn RE 1987. Experimental leishmaniasis in the Brazilian squirrel monkey (Saimiri sciureus): lesions, hematology, cellular, and humoral immune responses. J Med Primatol 16: 165-174.

Reed SG, Scott P 1993. T-cell and cytokine responses in leishmaniasis. Curr Opin Immunol 5: 524-531.

Reiner SL, Locksley RM 1995. The regulation of immunity to Leishmania major. Annu Ver Immunol 13: 151-177.

Richardson MD, Turner A, Warnock DW, Llewellyn PA 1983. Computer-assisted rapid enzyme-linked immunosorbent assay (ELISA) in the serological diagnosis of aspergillosis. J Immunol Methods 56: 201-207.

Ridley DS, Ridley MJ 1983. The evolution of the lesion in cutaneous leishmaniasis. J Pathol 141: 83-96.

Saravia NG, Weigle K, Segura I, Giannini SH, Pacheco R, Labrada LA, Gonçalves A 1990. Recurrent lesions in humans Leishmania braziliensis infection Reactivation or reinfection? Lancet 336: 398-402.

Sassi A, Louzir H, Bem Salah A, Mokni M, Bem Osman A, Dellagi K 1999. Leishmanin skin test, lymphoproliferative responses and cytokine production after symptomatic or asymptomatic Leishmania major infection in Tunisia. Clin Exp Immunol 116: 127-132.

Shearer MH, Dark RD, Chodosh J, Kennedy RC 1999. Comparison and caracterization of immunoglobulin $\mathrm{G}$ subclasses among primate species. Clin Diagn Lab Immunol 6: 953-958.

Sjölander A, Baldwin TM, Curtis JM, Handman E 1998. Induction of a Th1 immune response and simultaneous lack of activation of a $\mathrm{Th} 2$ response are required for generation of immunity to leishmaniasis. J Immunol 160: 3949-3957.

Wilson HR, Dickman BS, Childs GE 1979. Leishmania braziliensis and L. mexicana mexicana: experimental cutaneous infections in golden hamsters. Exp Parasitol 47: 270-83.

Wolf RE 1976. Immune response to Leishmania tropica in Macaca mulatta. J Parasitol 62: 209-214. 